\title{
A AVALIAÇÃO NO PROCESSO DE ENSINO E DE APRENDIZAGEM NO ENSINO SUPERIOR
}

\author{
Edilane Pizoni Oening ${ }^{1}$ \\ Elenice Padoin Juliani Engel ${ }^{2}$
}

\begin{abstract}
Resumo: Este trabalho visa verificar a concepção e os propósitos da avaliação no ensino superior. A avaliação é uma atividade de suma importância no processo de ensino e de aprendizagem, no entanto, se utilizada de maneira superficial pelos docentes, ela pode deixar de cumprir o seu papel. Pretende-se, por meio de uma análise teórica, buscar fontes que esclareçam o papel da avaliação no ensino superior e que norteiem seu uso, para que esta atividade seja uma ferramenta, não apenas de verificação da aprendizagem do aluno, mas de auxílio do docente na sua tarefa de formar cidadãos graduados. Como metodologia investigou-se os planos de ensino da quarta fase do curso de graduação de Letras da UNESC. Percebeu-se que a avaliação da aprendizagem se sobressai em relação a avaliação do ensino, e apesar de as atividades avaliativas alcançarem um caráter educativo, fica difícil afirmar se elas norteiam a prática pedagógica.
\end{abstract}

Palavras-chave: Avaliação. Processo de Ensino e de Aprendizagem. Planos de Ensino de Curso de Graduação.

\section{THE EVALUATION IN THE TEACHING AND LEARNING PROCESS IN UNDERGRADUATE EDUCATION}

\begin{abstract}
This paper aims to verify the conception and purposes of evaluation in undergraduate education. Evaluation is an extremely important activity in the teaching and learning process, however, if professors use it superficially, it may fail to fulfill its role. The intention of this paper is, through theoretical analysis, find sources that clarify the role of evaluation and guide its use, so that this activity is used as a tool, not only to verify the student's learning, but also to help the professors in their task of forming graduate citizens. As a methodology, the syllabuses of a fourth phase of the undergraduate degree course of Portuguese and Literature of UNESC were investigated. It was perceived that the evaluation of learning excels in relation to the evaluation of teaching, and although the evaluation activities reach an educational level, it is difficult to say if they guide the pedagogical practice.
\end{abstract}

\footnotetext{
${ }^{1}$ Acadêmica de Pós Graduação: Docência no Ensino Superior, UNESC Rua Hercílio Luz n191, Centro Criciúma 88801300 - eoening@hotmail.com.

2 Professora Orientadora, UNESC. Rodovia Alexandre Belolli, 2.250, Bairro 1른 Linha, 88816400 epj@unesc.net.
} 
Keywords: Evaluation. Teaching and Learning Process. Undergraduate Course Syllabuses.

\section{INTRODUÇÃO}

Atualmente, a temática da avaliação tem sido motivo de estudos e reflexões, neste contexto, este trabalho não tem a pretensão de buscar ou oferecer soluções mágicas, mas sim promover reflexões acerca da avaliação da aprendizagem, com foco especial no ensino superior.

No processo de ensino e de aprendizagem todas as atividades devem estar em consonância, inclusive a avaliação. A avaliação pode ser vista apenas como uma ferramenta para perceber se os alunos estão se apropriando do conteúdo proposto pelo docente, no entanto, seria importante que ela fosse além da nota. Existem várias formas de avaliar, assim como são diversas as percepções dos docentes em relação à avaliação e seu propósito, mas o que os docentes, em geral, têm como objetivo é que o aluno realmente aprenda e que o conhecimento construído em sala de aula seja usado em benefício da sociedade. Para que isso seja uma realidade é fundamental que a avaliação seja vista como parte do processo de ensino e de aprendizagem, não como mero instrumento de "cobrança" do professor para com o aluno. Neste sentido, também, considera-se que a avaliação é mais significativa quando não apenas a aprendizagem é avaliada, mas principalmente o ensino.

Apesar de a avaliação ter sido amplamente discutida até o momento, percebese ainda uma insegurança por parte dos professores na hora de decidir as formas avaliativas. Tradicionalmente, a avaliação tem sido vista como uma atividade de caráter quantitativo, na qual a aprendizagem do aluno seria avaliada, por meio de questões objetivas ou não, às quais seriam atribuídos valores numéricos representando a nota do aluno; as notas gerariam uma média, que definiria a aprovação ou reprovação do mesmo. Contudo, esse tipo de abordagem vem sendo 
criticado, por gerar estresse no aluno, exclusão dos alunos com maior dificuldade, ineficiência na verificação da aprendizagem, e principalmente por, não gerar mudanças na forma de ensino. Estudos sugerem que o principal propósito da avaliação deveria ser uma tomada de atitude no processo de ensino, levando em consideração que alunos aprendem de maneira singular. Neste caso, a avaliação deixa de ter o resultado escolar dos alunos como foco principal, e reserva este foco ao processo de ensino e de aprendizagem.

Neste estudo, pretende-se verificar as concepções de avaliação e qual o seu papel/propósito no processo de ensino e de aprendizagem no curso superior; compreender de que maneira o processo avaliativo pode auxiliar na aprendizagem do discente; analisar planos de ensino de um curso de graduação e relacionar as informações encontradas com a literatura acerca da avaliação.

Este artigo será construído por meio de uma pesquisa básica quanto à natureza, com abordagem qualitativa, descritiva quanto aos objetivos e documental em relação aos procedimentos técnicos.

\section{FUNDAMENTAÇÃO TEÓRICA}

\subsection{AVALIAÇÃO DE APRENDIZAGEM}

Todos os itens do plano de ensino são elaborados para que o processo de ensino e de aprendizagem realmente aconteça, para que os objetivos sejam alcançados. A avaliação também pode e deve manter este foco. Quando a avaliação se torna apenas um instrumento de verificação do aprendizado do aluno, com o intuito de gerar uma nota, deixa de ser uma atividade de sala de aula eficiente. As atividades avaliativas se bem elaboradas podem contribuir para melhorar a aprendizagem dos alunos e, desta forma, tornam-se uma prática metodológica coerente. Vários estudos mostram a necessidade de uma avaliação significativa, que tenha como quesitos: avaliar não o aluno, mas o ensino, para que o mesmo possa ser redirecionado se 
necessário; ser justa em benefício do aluno e, principalmente, que tenha um propósito que não enfatize a função burocrática, mas que cuide da aprendizagem.

Os estudos em avaliação deixam para trás o caminho das verdades absolutas, dos critérios objetivos, das medidas padronizadas e das estatísticas, para alertar sobre o sentido essencial dos atos avaliativos de interpretação de valor sobre o objeto da avaliação, de um agir consciente e reflexivo frente às situações avaliadas e de exercício do diálogo entre os envolvidos. (HOFFMANN, 2001, p. 15-16).

Segundo Luckesi (1995) quando o procedimento metodológico se resume em transmitir o conteúdo, aplicar uma atividade avaliativa, corrigi-la, entregar a nota e recomeçar um novo conteúdo não pode ser considerado um procedimento avaliativo, pois a atividade se resume na obtenção da nota com o pressuposto que a nota é o reflexo do que o aluno aprendeu. Neste caso, a avaliação não está sendo utilizada para ensinar ou aprimorar o conhecimento do aluno. $O$ aluno percebe a avaliação como algo desconectado do processo de ensino e de aprendizagem, deixando de valorizar a atividade em si. O professor que aceita a concepção de avaliação como geração de nota, perde a oportunidade de avaliar não só o que o aluno supostamente aprendeu, mas de avaliar o seu ensino, a sua prática pedagógica.

Luckesi (1995, p.33) afirma que "a avaliação pode ser caracterizada como uma forma de ajuizamento da qualidade do objeto avaliado, fator que implica uma tomada de posição a respeito do mesmo, para aceitá-lo ou para transformá-lo." Segundo o autor, a avaliação é, primeiramente, um "juízo de valor", ou seja, a partir de critérios pré-estabelecidos seja conferido uma afirmação qualitativa. $\mathrm{O}$ objeto avaliado será mais ou menos satisfatório, dependendo da aproximação ou distância do objetivo proposto. No entanto, essa qualificação é vista como "protótipo ou estágio de um processo." Desta forma, a avaliação "se faz com base nos caracteres relevantes da realidade", ou seja, "o juízo emergirá dos indicadores da realidade que delimitam a qualidade efetivamente esperada do objeto." (LUCKESI, 1995, p.33) Para finalizar, a avaliação requer uma tomada de decisão. A partir do julgamento de valor há a 
percepção das medidas a serem tomadas, a mudança de atitude aponta para um processo contínuo.

Nesta perspectiva, a avaliação deve ser um instrumento que beneficie os alunos, pois é por meio dela que o professor vai avaliar as suas práticas de ensino e vai buscar se aprimorar para que tais práticas realmente promovam a produção de conhecimento dentro e fora da sala de aula. Se a forma avaliativa proposta pelo professor gerar autorreflexão e proporcionar melhorias no ensino, consequentemente, os alunos serão beneficiados com uma aprendizagem significativa, que será internalizada e não apenas memorizada para a prova.

\begin{abstract}
A Avaliação é um processo abrangente da existência humana, que implica uma reflexão crítica sobre a prática, no sentido de captar seus avanços, suas resistências, suas dificuldades e possibilitar uma tomada de decisão sobre o que fazer para superar os obstáculos. É a forma de acompanhar o desenvolvimento dos educandos e ajudá-los em suas eventuais dificuldades. (VASCONCELLOS, 1995, p. 43).
\end{abstract}

De acordo com Vasconcellos (1995), é de suma importância que a avaliação não seja o principal objetivo da aula, afinal o aluno não está aprendendo só para fazer a avaliação. Ele está aprendendo para a vida. As atividades de avaliação devem ser consideradas instrumentos de auxílio dentro da sala de aula e não o objetivo final. Cabe ao professor minimizar o peso e a ênfase da nota sobre tais atividades. A utilização de diversas atividades é uma proposta coerente para essa abordagem, tais como seminário, trabalho em grupo, apresentação, debates entre outros. Atividades que incentivam os alunos a serem autônomos e buscarem o conhecimento fora do contexto escolar, assim como na sociedade e na realidade social na qual estão inseridos. O professor que adota a prova como avaliação também pode ir além da nota, pois se corrigir a prova em sala de aula com a participação dos alunos, ele estará disponibilizando aos mesmos a chance de tirar dúvidas nas questões da prova, como também dúvidas da matéria no geral, ou seja, dará espaço para questionamentos, tornando este momento rico em conhecimento. 
Vasconcellos (1998, p. 20) diz que é preciso mudar o paradigma, "para que a avaliação seja um instrumento de ajuda, deve ser reenfocada desde sua raiz." Ou seja, não basta mudar de nome, de prova para instrumento de avaliação por exemplo, é preciso que se tome providências a partir da avaliação, seja ela qual for. A concepção da avaliação precisa ser diferente da tradicional, se não houver uma mudança de postura, não adianta mudar a denominação. "As palavras não são neutras: 'prova' significa ter que provar algo a alguém, ao invés de se constituir uma forma de acompanhamento. Desejamos mudar a essência e não só a aparência da prática."

Em seus estudos, Libâneo (1994, p.195) afirma que "a avaliação é uma tarefa didática necessária e permanente do trabalho docente, que deve acompanhar passo a passo o processo de ensino e aprendizagem." Ainda ressalta que os resultados obtidos em atividades avaliativas no decorrer do trabalho conjunto entre professor e aluno devem ser relacionados com os objetivos propostos, com o propósito de verificar progressos e dificuldades tanto dos alunos quanto do professor, ou seja, a avaliação é o momento de reflexão acerca da qualidade do ensino/ professor e da aprendizagem/ aluno. Sendo assim, trata-se de uma tarefa complexa, que vai além da realização de provas e atribuição de notas. Apesar dos dados coletados serem quantitativos ou qualitativos, "a mensuração proporciona dados que devem ser submetidos a uma apreciação qualitativa".

Segundo Libâneo (1994), para que a avalição não seja considerada como um elemento isolado, visando somente o aspecto quantitativo, ela precisa atender três funções: pedagógico-didática, diagnóstica e de controle.

A função pedagógico-didática se refere aos objetivos gerais e específicos, bem como, aos meios e condições de atingi-los, uma vez que estes constituem o ponto de partida e os critérios para as provas e demais procedimentos avaliativos. A função diagnóstica se refere à analise sistemática das ações do professor e dos alunos, visando detectar desvios e avanços do trabalho docente em relação aos objetivos, conteúdos e métodos. Através desta função, a avaliação permeia todas as fases do ensino, assegurando $O$ seu aprimoramento permanente, possibilitando 0 cumprimento da função pedagógico-didática. A função de controle se refere à comprovação e à qualificação sistemática dos resultados da aprendizagem 


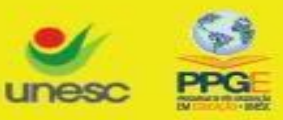

dos alunos, face a objetivos e conteúdos propostos. Através dessa função, são coletados os dados sobre o aproveitamento escolar que submetidos a critérios quanto à consecução de objetivos, levam a expressar juízos de valor, convertidos em notas ou conceitos. (LIBÂNEO 1994, p. 190)

Para Libâneo (1994), a avaliação trata-se de um "ato pedagógico", pois é por meio dela que o professor tem a oportunidade de mostrar suas qualidades de educador. Portanto, um bom educador disponibilizará a seus alunos atividades que tenham propósitos definidos no que diz respeito ao "desenvolvimento das capacidades físicas e intelectuais dos alunos face às exigências da vida social" (LIBÂNEO 1994, P.203).

Segundo Strieder et al (2014, p.72) a avaliação é "[...] um recurso pedagógico e educativo para auxiliar o educando e o educador a construir-se fazendo e sendo melhor em vida. [...] avaliar é uma ação amorosa, inclusiva, dinâmica e processual. Sua prática, sempre processual, requer acolher [...]os alunos como eles são". A avaliação, quando agendada para o final do semestre ou final do conteúdo, deixa os alunos com uma falsa sensação que apenas no final terão que dar retorno ao professor. Entende-se que quando o aluno e o professor assumem um acordo que toda a aula será considerada para a avaliação, o aluno se sente como participante principal do processo. A avaliação deixa de ser pontual e se torna processual, apesar de parecer algo mais difícil no início, aos poucos se tornará normal e não gerará o estresse comum nos dias de prova. O aluno aprenderá gradativamente por meio das atividades propostas pelo professor e perceberá que cada atividade é importante para o seu conhecimento, mesmo que esta seja uma atividade avaliativa. Por se tratar de atividades que se repetem no decorrer das aulas, elas serão curtas e objetivas, mas terão um efeito importante na prática pedagógica do professor.

Na avaliação processual, "o objetivo [...] não será a aprovação ou reprovação do educando, mas a oferta de novos e diferentes espaços aprendentes na expectativa de consequente desenvolvimento" (STRIEDER et al 2014, p.72). Assim, o professor deixará de ser o único responsável pela produção do conhecimento e terá o melhor aliado de todos, o aluno. Essa abordagem leva em consideração o conhecimento 
prévio do aluno, o que foi aprendido ou aprimorado na aula e inclusive o que o aluno ainda vai aprender. Este tipo de avaliação confere uma abordagem dinâmica e tende a diagnosticar a aprendizagem e o ensino para melhorá-la. Conforme Strieder (2014, p.118) "Uma avaliação para qualificar a aprendizagem, identifica problemas, elabora estratégias de solução, provoca para rever os rumos quando necessários e retoma para dinamizar a aprendizagem de todos os envolvidos." Strieder (2014) também ressalta que nenhuma avaliação é concebida isolada do processo ensino e de aprendizagem, ou seja, a avaliação precisa estar em consonância com a metodologia de ensino, os objetivos gerais e específicos da disciplina.

\subsection{O PROFESSOR E O PROCESSO DE ENSINO E DE APRENDIZAGEM}

Tradicionalmente, a sala de aula é um ambiente de ensino e de aprendizagem, assim todas as atividades que acontecem neste ambiente devem ter como objetivo a produção de conhecimento. O tempo vivido pelos alunos durante a graduação deve ser bem aproveitado, pois é durante a graduação que os acadêmicos terão a chance de se preparar para a futura profissão. Quanto mais atividades promovam o conhecimento, melhor preparado o aluno estará para o mercado de trabalho e, principalmente, para a vida em sociedade. Entende-se que a educação tem a função de conferir autonomia ao aprendiz, não se trata, portanto, de uma tarefa simples. Petraglia e Almeida (2006, p.7) destacam que:

Educação é processo complexo. Envolve pessoas tornando-se constantemente pessoas. Educação é também caminho: caminhar interativo, relacional, construído no horizonte do ser gente. Algumas levam à emancipação e outras à dominação, à subjugação, à fragmentação. Ser um ser vivo é deveras complexo.

Quando o professor tem esta concepção de ensino, ele será norteado pelas práticas que visam a construção do conhecimento. Esse conhecimento é construído quando as práticas utilizadas vão além do repasse de informação. Quando um conteúdo é repassado aos alunos e, posteriormente, cobrado em provas, sem que 
haja diálogo entre professores e alunos, o conhecimento pode ser superficial, ou seja, o aluno não se torna parte do processo de ensino e de aprendizagem, ele não passa de um espectador. É fundamental que o aluno se sinta parte da construção de seus conhecimentos e esteja engajado neste processo.

De acordo com Bisognin (2005, p.178) “[...] o aluno aprende, constrói conhecimento, passa a ver a realidade com um outro olhar, problematizando, elaborando, comunicando, avaliando, construindo relações entre teoria e prática". Assim, o professor quando assume o compromisso de ser um educador e se torna responsável pela aprendizagem de seus alunos deve promover atividades de aula que sejam significativas. Atividades que tirem o aluno da posição passiva, que o façam refletir, analisar, buscar soluções para situações reais, que tirem o aluno da ignorância. O professor tem a obrigação de criar pontes entre a prática e a teoria. Embora, o aluno também precise ser curioso, buscar informações fora do ambiente escolar, é na sala de aula que ele será instigado a enxergar além da teoria, pois a teoria pode ser cansativa, enquanto que a aplicação da teoria na prática é inspiradora e traz satisfação e significado ao conteúdo trabalhado (BISOGNIN, 2005).

Severino (2002) ressalta a necessidade de educadores que vão além de ensinar o aluno a pensar, que despertem o gosto pelo pensar, pelo aprender e pelo diálogo. O diálogo entre professores e alunos é insubstituível. É por meio do diálogo que o aluno se reconhecerá como um indivíduo que pode compartilhar o que sabe, que pode expressar sua opinião, e que principalmente sua voz será ouvida, primeiramente pelos professores e colegas e, posteriormente, pela sociedade.

O educador que abre espaço à discussões e debates na sala de aula aprende junto com o aluno. O processo de ensino e de aprendizagem não se trata de uma via de mão única, nele tanto alunos quanto professores buscam o crescimento pessoal e intelectual. O aluno, quando valorizado e respeitado, torna-se um ser aberto ao conhecimento.

É imprescindível que o professor desenvolva a habilidade de saber ouvir. Ouvir, equilibrando a razão e as emoções para respeitar o que vem do outro, pode fazer o grande diferencial. [...] quando os alunos e professores dialogam lidam com presenças e ausências, silêncios e manifestações, dúvidas, certezas, alegrias e conflitos. O ambiente de diálogo transforma-se num 
espaço de discussão, não conflitivo, mas um espaço de permutas, no qual histórias de vidas, carregadas de conhecimentos prévios, de valores e de vivências contribuem para a aprendizagem mútua. (STRIEDER et al, 2014 p.150).

Segundo Freire (1996), o homem só consegue modificar a realidade quando ele percebe que é capaz de fazer a mudança. Neste sentido, a educação precisa ter como objetivo principal conscientizar o homem de sua capacidade, por meio de uma atitude crítica, que vá além da reflexão, que alcance a ação necessária para promover a mudança da realidade para uma sociedade melhor para todos. Cabe aos educadores, utilizando suas práticas pedagógicas, empoderar seus alunos, tornandoos cidadãos, protagonistas de suas vidas. Freire (1996, p.39) ainda ressalta que:

É preciso que a educação esteja - em seu conteúdo, em seus programas e em seus métodos - adaptada ao fim que se persegue: permitir ao homem chegar a ser sujeito, construir-se como pessoa, transformar o mundo, estabelecer com os outros homens relações de reciprocidade, fazer a cultura e a história [...].

Quando se fala de conteúdo e métodos na educação, a avaliação tem seu papel importante, ou seja, ela faz parte do planejamento de ensino, e por isso deve, também, ensinar.

\subsection{A INSTITUIÇÃO E A AVALIAÇÃO DA APRENDIZAGEM}

De acordo com o Projeto Pedagógico Institucional (PPI), relatado no Plano de Desenvolvimento Institucional (PDI) 2018-2022, a UNESC - Universidade do Extremo Sul Catarinense, entende por uma sociedade ideal aquela que é estruturada sob os princípios de democracia e igualdade e que seja centrada do desenvolvimento humano, na qual os interesses coletivos se sobreponham aos individuais. Para que esta sociedade seja uma realidade, a instituição pretende garantir a todos o acesso ao conhecimento científico e tecnológico com a missão de formar cidadãos críticos, participativos e propositivos, que tenham consciência das riquezas nacionais, humanas e naturais e de seu papel de transformador no mundo, por meio do seu 
empreendedorismo e comprometimento com a preservação da vida no planeta. Contudo, para contribuir à sociedade dentro dessa perspectiva, a Universidade deve se comprometer com qualidade de ensino e educação integral, que contribua para a formação de profissionais capazes de atuar como agentes de transformação e construção da sociedade, os quais sejam profissionais com competências, capazes de "preservar o conhecimento historicamente acumulado e de construir novos conhecimentos por meio da pesquisa e da prática reflexiva (não reiterativa, de mera repetição)." (PDI UNESC, 2018, p.23)

Conforme seu PPI (2018), a UNESC entende que processo de ensinoaprendizagem deve ser comprometido com valores essenciais que visem o bem-estar da comunidade e a melhoria da qualidade de vida do ser humano. Para isso, a educação deve ser inclusiva, que respeite, valorize e reverencie as diferenças. Neste contexto, torna-se relevante reavaliar constantemente as formas e critérios de seleção de professores e construir uma política de avaliação de suas atividades, ou seja, a política adotada pela instituição, é que haja uma avaliação permanente das atividades de sala de aula, não apenas da aprendizagem do aluno, mas especialmente a avaliação do ensino.

Para a instituição é de suma importância que o corpo docente seja qualificado e conhecedor do contexto social no qual está inserido, e que não seja um mero reprodutor de ideologias. É imprescindível que o corpo docente seja capaz de formular uma proposta metodológica, na qual as aulas não se tornem somente reprodução de conteúdo, mas que possibilitem a reflexão e a construção de conhecimentos. De acordo com o documento analisado, nesta universidade

[...] procura-se trabalhar com uma proposta de avaliação diagnóstica, processual, inclusiva e emancipatória. A avaliação do processo ensinoaprendizagem compreende o acompanhamento do ensino e da aprendizagem/apropriação de conhecimento, a autoavaliação, avaliação da relação professor-aluno e aluno-aluno. Para isso, faz-se necessário rever a concepção de aprendizagem e objetivos das disciplinas e dos programas tornando a relação entre aluno e professor mais próxima." (PDI UNESC, 2018, p. 25) 
No regimento geral da UNESC, aprovado pela Resolução n. 07/2017/ CSA, o Art. 87 afirma que "A avaliação do processo de ensino-aprendizagem, corresponsabilidade de todos os sujeitos envolvidos, estará fundamentada no Projeto Político Pedagógico Institucional e será processual, com preponderância dos aspectos qualitativos sobre os quantitativos." No Art. 88, ressalta-se que "a Coordenação e o Colegiado de curso de graduação proporão procedimentos de avaliação e recuperação da aprendizagem que assegurem o desenvolvimento da avaliação processual." No artigo 89, fica explícito que é de responsabilidade do docente a organização do processo avaliativo e do registro dos resultados, para isso ele deve: participar da definição dos procedimentos de avaliação no colegiado do curso; usar diversos instrumentos de avaliação da aprendizagem; analisar, registrar os resultados da avaliação, assim como analisa-los e discuti-los e disponibilizar a recuperação dos conteúdos e notas aos acadêmicos. No Art. 90 do mesmo documento, fica estipulado que o docente deverá aplicar, no mínimo, três avaliações, das quais duas devem ser individuais. Já na sequência o Art. 91 declara que para fim de registros, as avaliações são expressas por meio de notas de zero a dez. E a seguir no Art. 92, fica expresso que apenas os alunos com média igual ou superior a seis serão aprovados.

O Projeto Pedagógico Do Curso (PPC) De Letras Língua Portuguesa - Licenciatura, 2016, no que tange à avaliação, afirma seguir as resoluções aprovadas no Regimento Geral da UNESC, a qual ressalta a corresponsabilidade dos sujeitos envolvidos no processo de ensino/ aprendizagem, a avaliação processual e a abordagem qualitativa dos resultados. O curso entende que uma avaliação processual do desempenho acadêmico, é "uma concepção de avaliação que esteja integrada ao processo de ensino-aprendizagem, objetivando o acompanhamento do desempenho do acadêmico e do professor." (PPC CURSO DE LETRAS, 2016. p.35)

No PPC do curso (2016, p. 35- 36) afirma-se que os conteúdos e dúvidas, além de serem revisados antes da realização da atividade avaliativa, eles são discutidos no momento da entrega do material corrigido pelo professor, disponibilizando a revisão dos conteúdos que os acadêmicos demonstrarem dificuldades. Se houver a necessidade de recuperação de aprendizagem, outras ferramentas podem ser 
utilizadas, tais como: realização de seminários, saídas de campo, estudos dirigidos, análise escrita de vídeos, relatórios de aulas práticas e ou de atividades, resolução de casos clínicos, análise de artigo entre outras, com o intuito de gerar reflexão e redirecionamento da proposta de aula. Os critérios de avaliação do Curso de Letras são apresentados aos discentes ao início de cada semestre por meio do plano de ensino.

\section{METODOLOGIA}

A metodologia adotada nesta pesquisa é básica quanto à natureza, uma vez que "[...] procura aumentar o conhecimento sobre o homem, a natureza e a própria humanidade, [...] faz crescer o patrimônio comum da ciência pela descoberta de leis e efeitos." (BOAVENTURA, 2012, p.56)

A abordagem adotada é a qualitativa, pois de acordo com Bogdan e Biklen (1994 apud Boaventura, 2012) o material a investigar não está associado à operacionalização de variáveis, mas a investigação de fenômenos, enfatizando sua complexidade e seu contexto natural, os quais são ricos em detalhes descritivos.

A pesquisa é descritiva quanto aos objetivos, pois busca observar, registrar, analisar e correlacionar fatos ou fenômenos, sem a intenção de manipulá-los, com o intuito de descobrir, de maneira ampla, a relação e conexão entre o objeto de estudo e a vida social, política, econômica dentre outros aspectos do comportamento humano, como indivíduo isolado ou inserido num contexto social. Entende-se que "[...] a pesquisa descritiva, em suas diversas formas, trabalha sobre dados ou fatos colhidos da própria realidade." (CERVO et al, 2006, p. 62)

Quantos aos procedimentos técnicos, a pesquisa é documental, pois os planos de ensinos foram investigados com a compreensão que tais documentos destacam o processo avaliativo utilizado na graduação deste curso. De acordo com Cervo et al (2006) a pesquisa por meio de documentos, abarca a intenção de descrever e analisar usos, costumes e tendências que permitam estudar a realidade. 


\section{APRESENTAÇÃO E DISCUSSÃO DOS RESULTADOS}

Foram analisados 7 planos de ensino referentes às disciplinas da quarta fase do curso de Letras - Habilitação Língua Portuguesa no período 2018/2, modalidade presencial. As disciplinas são: Fonética e Fonologia, Seminário de práticas de Linguagem I, Literatura III, Prática de Análise Linguística, Estágio Supervisionado de Língua Portuguesa I, Libras e Sintaxe do Português II. Os planos de ensino da quarta fase foram selecionados por se tratarem da fase do curso que estava vigente durante o início do artigo.

Cada disciplina foi avaliada, a partir do plano de ensino publicado pelo professor responsável, quanto aos critérios de avaliação, buscando verificar as formas avaliativas predominantes em cada uma delas.

A disciplina de Fonética e Fonologia usa como critério de avaliação três produções escritas, 2 individuais e uma em dupla. Entende-se que se trata de produção textual devido ao item que define que em todos os trabalhos será exigida concordância com as regras da ABNT de formulação de trabalho científico. No plano de ensino desta disciplina fica explicito que os detalhes do desenvolvimento de cada trabalho serão explicados em sala, o que demonstra que haverá diálogo entre professores e alunos referente às avaliações propostas. Ainda nesta disciplina, verifica-se que a recuperação de conteúdo acontecerá de maneira processual, por meio de correção, discussão, debate e conversas em sala de aula ou no ambiente virtual de aprendizagem (AVA) das avaliações escritas.

A disciplina de Seminário de Práticas de Linguagem I terá três avaliações, sendo elas: resumo comentado das leituras feitas em sala, apresentação de atividade simulada, e produção de uma crônica, sendo que cada uma terá peso 10. Afirma-se no plano de ensino que a recuperação do conteúdo, se necessária acontecerá ao longo do processo das aulas.

Em Literatura III, a professora aplica três avaliações, das quais uma é aparentemente "prova", pois se intitula apenas por "avaliação individual", as outras são um Ensaio, e uma Intervenção Literária/ Crônica Literária. Neste plano de ensino, 
explicita-se que todos os critérios avaliativos serão pré-definidos junto à turma e expostos pela professora no AVA, assim como a recuperação de conteúdo acontecerá por meio de correção das atividades escritas em sala de aula, enquanto que as atividades de grupo se dará por meio de discussões e postagens.

Em Prática de Análise Linguística, serão aplicadas três atividades avaliativas, tais como apresentação de seminário, produção de artigo de opinião e atividade de retextualização. As três avaliações têm peso 10 cada. Verifica-se que a recuperação do conteúdo dar-se-á por meio da discussão das atividades em sala de aula.

$\mathrm{Na}$ disciplina Estágio Supervisionado de Língua Portuguesa I, haverá uma avaliação individual, a qual poderá ser refeita caso o acadêmico não atinja a média. $A$ segunda trata-se de uma produção escrita e apresentação oral, esta atividade encontra-se também no item Metodologia de Ensino Aprendizagem, o que promove a avaliação como estratégia de ensino, ou seja, os alunos aprendem enquanto são avaliados. A terceira avaliação proposta é a elaboração de plano de ensino e apresentação de uma aula simulada.

Na disciplina de Libras, uma atividade avaliativa tem conceito de "prova teórica individual" com peso 10, enquanto que a outra se denomina como "prova com duas questões discursivas" com peso 5. A terceira avaliação é uma produção oral/gestual/textual a partir de um artigo com peso 5. E por fim a quarta atividade é a interpretação/ tradução de vídeo produzido pela professora. Neste plano de ensino está descrito que os critérios de avaliação processual e recuperação de conteúdos estão de acordo com as resoluções vigentes da universidade, os quais serão apresentados e discutidos com os alunos no início e durante o semestre letivo. Ainda ressalta que as avaliações serão corrigidas e devolvidas antes das avaliações seguintes, haverá recuperação de aprendizagem ao longo do semestre, por meio de atividades de revisão de conteúdo e os alunos que não atingirem a média terão a chance de recuperação de nota.

$\mathrm{Na}$ disciplina Sintaxe do Português II, verificou-se que três das quatro avaliações são denominadas como "prova". Sendo que duas provas terão peso 8 cada, enquanto que uma terceira avaliação será a socialização das análises em grupo 
com peso 4. A quarta avaliação será uma prova com peso 4 que adicionada à elaboração de uma resenha com peso 6 somará 10. A resenha será orientada em sala de aula e encontra-se destacada no item Metodologia de Ensino Aprendizagem. A recuperação do conteúdo dar-se-á por meio da correção das atividades escritas em sala de aula, assim como a atividade em grupo se dará por meio de discussões.

Analisando os planos de ensino consultados pode-se verificar que o processo de avaliação no curso de letras está bem estruturado no que tange avaliar a aprendizagem do aluno e não apenas ser um processo isolado para gerar notas. Pois, segundo Luckesi (1995), para que haja, de fato, um procedimento avaliativo, a metodologia deve ir além de transmitir o conteúdo, aplicar uma atividade avaliativa, corrigi-la, entregar a nota e recomeçar um novo conteúdo. De acordo com os planos de ensino, os professores demonstram grande interesse em proporcionar algo diferente deste ciclo - conteúdo, avaliação, nota, novo conteúdo - tais como discussão acerca das atividades avaliativas, correção das atividades em sala de aula, nas quais os alunos têm a oportunidade de questionar e refletir acerca do conteúdo ministrado, solucionando dúvidas e gerando conhecimento.

As atividades avaliativas propostas, em geral, estão alinhadas com a produção de conhecimento. Quando o professor adota como atividade avaliativa a produção textual, tal como artigo, resumo, retextualização, ensaio, resenha ou mesmo apresentação áudio visual, ele está propondo que o aluno aprenda enquanto está aplicando uma atividade avaliativa. Vasconcellos (1995) afirma que a avaliação não deve ser o principal objetivo da aula, mas que deve ser considerada como um instrumento de auxílio da aprendizagem. Assim sendo, quando o aluno produz um texto ou uma apresentação, ele está aprendendo a organizar, socializar e memorizar seus conhecimentos.

A escrita permeia todas as profissões, contudo é de suma importância que os alunos estejam familiarizados com a produção textual. O Curso de Letras, particularmente, tem como característica a produção de textos, e é importante que as avaliações também utilizem esse viés. Libâneo (1994) destaca que a avaliação é um ato pedagógico e que as atividades propostas devem proporcionar o desenvolvimento 
físico e intelectual dos alunos levando em consideração as exigências sociais. Podese afirmar, portanto, que as atividades avaliativas propostas desenvolvem o intelecto dos alunos, preparando-os para a vida social.

Vários planos mencionam que as atividades serão discutidas com os alunos antes e depois de acontecerem, gerando diálogo entre professor e aluno e permitindo com que o aluno participe das decisões em sala de aula. Todas as disciplinas expõem três ou mais atividades avaliativas, sugerindo que a avaliação acontece de maneira processual e não pontualmente no final do semestre. Segundo Strieder et al 2014, a avaliação processual possibilita a oferta de atividades que gerem o desenvolvimento e não apenas a aprovação ou reprovação do acadêmico.

A quantidade e variedade das avaliações estão em consonância com o PDI e o regimento geral da instituição, pois tais documentos sugerem que haja no mínimo três avaliações, que tais atividades sejam aplicadas de maneira processual e que sejam diversificadas levando em consideração o desenvolvimento da aprendizagem do educando. O quesito recuperação também é claramente salientado nos planos de ensino, tal como cita o regimento geral da UNESC e o PPC do curso de Letras.

Apesar de as atividades avaliativas apresentarem características positivas no contexto de avaliação da aprendizagem, é impossível afirmar se as atividades avaliativas descritas nos planos de ensino exercem a função de avaliar o ensino e gerar mudanças quando necessárias. Tanto os documentos da instituição, como os estudiosos citados neste trabalho ressaltam o propósito de avaliar o processo de ensino e de aprendizagem. Sendo que a avaliação deve ser usada para perceber se os alunos estão se apropriando do conteúdo, caso isso não ocorra, ela tem a função de nortear o professor na produção da sua prática pedagógica. Cabe ao professor ter a sensibilidade de perceber, por meio de suas atividades, a necessidade de mudar a sua prática e disponibilizar atividades diferentes que auxiliem na aprendizagem do aluno e principalmente na sua autonomia.

\section{CONCLUSÃO}


Conclui-se que a avaliação do processo ensino e de aprendizagem está em destaque na educação, o que está proporcionando grandes mudanças no modelo tradicional implantando no sistema educacional. Apesar de mudanças significativas no âmbito da avaliação, ainda há muito espaço para desenvolvimento e aprimoramento das práticas pedagógicas. De acordo com o acervo a cerca deste tema, foi possível verificar semelhanças no que tange as concepções e propósitos da avaliação acadêmica. A literatura levanta reflexões no contexto escolar, pois o contexto atual tende a dar ênfase à avaliação da aprendizagem e muitas vezes menospreza a avaliação do ensino.

Percebe-se que a avaliação também pode ser educativa e auxiliar no processo de ensino e de aprendizagem, seja por meio de atividades que proporcionem a produção do conhecimento, ou por meio de providências tomadas a partir dos levantamentos feitos na atividade avaliativa. Ou seja, a avaliação não é o objetivo final da aula e sim um instrumento para auferir os progressos e dificuldades tanto dos alunos quanto dos professores.

A análise dos planos de ensino proporcionou uma visão geral nas atividades propostas, assim como atividades de recuperação e discussão em sala de aula. A literatura pesquisada deu subsídios para que a análise dos planos de ensino fosse possível. Contudo, apesar de o PPI da instituição definir que a avaliação seja: "diagnóstica, processual, inclusiva e emancipatória", a avaliação ainda apresenta traços tradicionais, tal como ter peso 10, por exemplo. Os planos de ensino buscam seguir as diretrizes propostas e apresentar atividades diversas. No entanto, é preciso acreditar que as avaliações estejam indo além das notas e realmente gerando as mudanças necessárias para uma educação exitosa.

Todavia, o estudo e a pesquisa são limitados e estão abertos a novas pesquisas acerca da avaliação no processo de ensino e de aprendizagem.

\section{REFERÊNCIAS}


BISOGNIN, Edir Lucia. Abordagens metodológicas no ensino da História da Arte. In: HERNÁNDEZ, Fernando; OLIVEIRA, Marilda de Oliveira. A formação do professor e o ensino das artes visuais. Santa Maria: Ed. UFSM, 2005, pp 176-186.

CERVO, Amado Luiz; BERVIAN, Pedro Alcino; DA SILVA, Roberto. Metodologia Científica. São Paulo: Pearson Prentice Hall, 2007.

FREIRE, Paulo. Pedagogia da Autonomia: saberes necessários à prática educativa. São Paulo: Paz e Terra, 1996.

FREIRE, Paulo. Pedagogia da autonomia: saberes necessários à prática educativa. 43. ed. Rio de Janeiro: Paz e Terra, 2011.

FREIRE, Paulo. Pedagogia do oprimido. São Paulo: Paz e Terra, 1996.

HOFMANN, Jussara. Avaliação mitos \& desafio: uma perspectiva construtivista. Porto Alegre: Mediação, 1991.

HOFMANN, Jussara. Avaliar para promover: as setas do caminho. Porto Alegre: Mediação, 2001.

LIBÂNEO, José Carlos. Didática. São Paulo: Cortez, 1994.

LUCKESI, C. A avaliação da aprendizagem escolar. São Paulo: Cortez, 2009.

PETRAGLIA, Izabel; ALMEIDA, Cleide (Orgs.). Estudos de complexidade. São Paulo: Xamã, 2006.

PIMENTA, Selma G. (org.) Saberes pedagógicos e atividade docente. São Paulo: Cortez, 1999.

SEVERINO, Antônio Joaquim. Educação e transdisciplinaridade. Rio de Janeiro: Lucerna, 2002.

STRIEDER, Roque; BENVENUTTI, Dilva Bertoldi; BAVARESCO, Paulo Ricardo. Avaliação como oportunidade de aprendizagem: um olhar transdisciplinar. Campinas, SP: Mercado de Letras, 2014.

UNESC. Universidade do Extremo Sul Catarinense. Resolução n. 07/2017/CSA. Aprova o Regimento Geral da Universidade do Extremo Sul Catarinense. UNESC: UNESC, 2017. 


\section{$1 \quad \approx$}

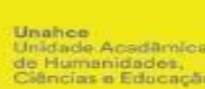
ediunesc

Criar Educação, Criciúma, v. 10, no1, jan/jul 2021.- PPGE - UNESC - ISSN 2317-2452

UNESC. Universidade do Extremo Sul Catarinense. Resolução n. 01/2011/. Câmara De Ensino De Graduação. Aprova critérios de avaliação processual e recuperação para os cursos de graduação da UNESC. UNESC: UNESC, 2011.

UNESC. Universidade do Extremo Sul Catarinense. Projeto Político-pedagógico Institucional. Criciúma, Coordenadoria de Planejamento e Desenvolvimento Institucional, UNESC, 2016.

VASCONCELLOS, Celso dos S. Avaliação da aprendizagem: práticas de mudança - por uma práxis transformadora. São Paulo: Libertad, 1998.

VASCONCELLOS, Celso dos S. Avaliação: concepção dialética-libertadora do processo de avaliação escolar. São Paulo: Libertad, 1995.

Recebido novembro de 2020

Aprovado abril de 2021 